\title{
The effect of housing on calving behavior and calf vitality in Holstein and Jersey dairy cows
}

\author{
M. Campler, L. Munksgaard, and M. B. Jensen ${ }^{1}$ \\ Department of Animal Science, Aarhus University, PO Box 50, 8830 Tjele, Denmark
}

\section{ABSTRACT}

The present study investigated how calving behavior and calf vitality in Holstein and Jersey dairy cows were affected by housing during the final 4 wk precalving. One hundred twenty-one cows (36 primiparous and 85 multiparous) were moved either to a group pen with deep straw bedding or into freestall housing $4 \mathrm{wk}$ before the expected calving date. Individual straw-bedded maternity pens were placed adjacent to the straw-bedded group pens, and cows were moved to the maternity pens before calving. Cows that spent more than $12 \mathrm{~h}$ in the maternity pen before calving and calved unassisted were included in this study (39 multiparous cows and 15 primiparous cows). Dams were observed from $6 \mathrm{~h}$ before calving until $6 \mathrm{~h}$ after calving. The time from the onset of rhythmical abdominal contractions (defined as the onset of stage II labor), the time from a visible amniotic sac, and the time from visible calf feet until the birth of the calf were recorded. Furthermore, the cows' latency to stand up after birth was recorded. Calves were observed during the first $6 \mathrm{~h}$ after birth and the latency to first standing attempt, to first successful standing, to first suckle attempt, and to first successful suckling were recorded. Cows previously housed in straw pens expelled the calf faster once the calves' feet were visible compared with cows previously housed in freestalls. Multiparous cows stood sooner and licked their calf sooner after birth compared with primiparous cows. Jersey calves of cows previously housed in straw pens also stood up and suckled their dams sooner compared with Jersey calves of cows previously housed in freestalls. Holstein cows previously housed in straw pens tended to stand up sooner compared with Holstein cows previously housed in freestalls. These results suggest that a longer period of housing on deep-bedded straw compared with freestalls with mattresses before calving may facilitate the calving process, whereas the effect on calf vitality needs further investigation.

Key words: dairy cow, calving, transition, labor

Received August 8, 2014.

Accepted November 30, 2014.

${ }^{1}$ Corresponding author: margitbak.jensen@agrsci.dk

\section{INTRODUCTION}

The transition period around calving is a critical period in a dairy cow's life (Grummer, 1995; Mulligan and Doherty, 2008) and there is increased interest in housing and management practices to ease the calving process. The distance that the cow is moved before calving is a concern, and producers have recently started to implement close-up pens adjacent to the maternity pens so that the cow is moved a shorter distance when calving is imminent. However, moving cows too close to calving has been shown to disrupt the calving process (Proudfoot et al., 2013). In some instances, these closeup pens are deep-bedded straw pens as an alternative to freestalls, because it is known that cows spend more time lying down on deep-bedded straw compared with freestalls (Phillips and Schofield, 1994; Fregonesi et al., 2009). This is likely due to better comfort while lying on deep straw, but deep straw bedding may also provide better traction when transitioning between lying and standing; dairy cows lie down for longer and change posture more frequently on soft surfaces compared with hard surfaces (Tucker et al., 2003; Calamari et al., 2009). Furthermore, a deep-bedded lying area has been found to improve leg and hoof health (Phillips and Schofield, 1994; Weary and Taszkun, 2000; Livesey et al., 2002) and reduce the occurrence of lameness (Cook et al., 2004).

The opportunity for dairy cows to lie down and get up safely and comfortably may be of increasing importance during the weeks precalving, due to the growing fetus, as well as on the day of calving, when the cow becomes more restless (Lidfors et al., 1994; Campler et al., 2014). More opportunity for locomotion may also be advantageous, because exercise during the final $6 \mathrm{wk}$ before parturition results in improved ease of calving and earlier release of the placenta (Lamb et al., 1979). Similar results are reported in sows (Hale et al., 1981; Ferket and Hacker, 1985) as well as in humans (Clapp, 1990; Prather et al., 2012).

Ease of calving may also affect calf vitality and health. Difficult or prolonged labor increases the risk of stillbirth and calf mortality (Murray and Leslie, 2013) and reduces calf vigor (Barrier et al., 2012). Therefore, any 
positive effects of housing on ease of calving may also improve calf vigor. Calf vigor may be assessed through general appearance, but the propensity to stand and suckle soon after birth is a behavioral indicator of calf vitality (Barrier et al., 2012).

The potential effect of housing on deep-bedded straw compared with freestalls during the dry period on ease of calving and calf vitality has not yet been investigated. The aim of the study was to investigate the effect of straw pen or freestall housing for 4 wk before expected calving date on the calving process and calf vitality in Holstein and Jersey dairy cows. We hypothesized that housing in deep-bedded straw pens during the last $4 \mathrm{wk}$ before parturition compared with housing in freestalls would result in increased ease of calving and improved calf vitality.

\section{MATERIALS AND METHODS}

\section{Animals, Housing, and Management}

Seventy-seven Holstein cows (54 multiparous, parity $=1.6 \pm 0.1$, mean $\pm \mathrm{SE}$, and 23 primiparous) and 44 Jersey cows (31 multiparous, parity $=1.5 \pm 0.1$, mean $\pm \mathrm{SE}$, and 13 primiparous) were included in the study conducted from December 2010 to August 2011 at the Cattle Research Centre, Tjele, Denmark. When the cows were dried off $8 \mathrm{wk}$ before calving, the BW of the experimental cows were 698 (SD 75) kg (Holstein) and 511 (SD 37) kg (Jersey) for multiparous cows, and 633 (SD 49) $\mathrm{kg}$ (Holstein) and 449 (SD 75) kg (Jersey) for primiparous cows. The birth weights of the calves were 44 (SD 7.7) $\mathrm{kg}$ (Holstein) and 32 (SD 7.2) kg (Jersey). Only clinically healthy cows entered the experiment. Cows grouped by breed were housed loose in a barn with partially curtained sidewalls and freestalls (1.85 $\mathrm{m} \times 1.35 \mathrm{~m}$ and $1.65 \mathrm{~m} \times 1.20 \mathrm{~m}$, length to brisket board, Holstein and Jersey, respectively), which were bedded with geotextile mattresses (Comfy Cushion, Canarm/BSM, Canarm Ltd., Brockville, ON, Canada) and topped with a thin layer of sawdust. The alleys had concrete slatted flooring (slats $=15 \mathrm{~cm}$, spacing $=4$ $\mathrm{cm})$ and cows were milked by an automatic milk robot system (DeLaval, Tumba, Sweden) under zero-grazing conditions. Self-filling water troughs and automatic feeders (Insentec B.V, Marknesse, the Netherlands) were used throughout the barn except for the maternity pens, which had feed troughs and self-filling water bowls. Fresh feed was provided every morning and topped up 3 times during the day between 0600 and $2100 \mathrm{~h}$. The feeders were emptied at least twice a week (more frequently if feed needed to be exchanged due to warm weather). Alleys were scraped continuously by automatic cleaning robots (Lely Discovery, Lely Holding, Maassluis, the Netherlands).

\section{Experimental Design}

Cows were dried off in a separate pen with freestalls equal to the general housing conditions described above and located in the same barn 8 wk before their expected calving date. Within breed and parity, cows were allocated to 1 of 2 housing treatments balanced for date of expected calving: freestalls (FS) or deep-bedded straw pack (DS), to which they were moved at 4 wk before their expected calving date. Cows on the FS treatment were moved to a precalving pen with freestalls identical to those in the general housing conditions described above. Cows on the DS treatment were moved to 1 of 2 DS pens, each $13.6 \mathrm{~m} \times 7.0 \mathrm{~m}$ and consisting of a deep-bedded straw area $(10.0 \mathrm{~m} \times 7.0 \mathrm{~m}$, minimum straw depth $=0.5 \mathrm{~m})$ and a feeding area $(3.6 \mathrm{~m} \times 7.0$ $\mathrm{m}$ ), with slatted flooring (slats $=15 \mathrm{~cm}$, spacing $=4$ $\mathrm{cm})$ and 5 automatic feed bins and self-filling water troughs. Holstein and Jersey cows on the FS treatment were housed in separate group pens, but cows of the 2 breeds were housed together in the 2 DS pens. This was due to the smaller number of Jersey cows compared with Holstein cows and the limited number of DS pens. The DS was adjacent to the maternity pens and the maximum distance a cow had to be moved to an individual maternity pen was $10 \mathrm{~m}$. In contrast, cows housed in FS had to be moved a maximum of 50 $m$ to an individual maternity pen. Group compositions in both treatments were dynamic as new cows entered both groups on Wednesdays, 4 wk before their expected calving date. Stocking densities were kept at approximately 2 cows per feeder in both systems and 1 cow per freestall in FS and a maximum of 10 cows per pen in DS. The straw in DS was replenished regularly according to normal barn maintenance procedures. Based on the expected calving date and physical and behavioral signs of calving (i.e., loose pelvic ligaments, tense udder, or restlessness), cows were moved to an individual maternity pen. The intention was to move cows as close to the actual calving date as possible without interrupting the calving process while ensuring that no calves would be born outside the maternity pens. This precaution led to cows being moved a few days (1 to 5 d) before the actual calving date due to the difference between expected and actual calving dates. The maternity pen $(4.0 \mathrm{~m} \times 3.1 \mathrm{~m})$ had concrete flooring topped with a $26-\mathrm{mm}$ dual-layered rubber mat (18-mm hard rubber base and 8-mm soft pebble top; AAG Aalborg Gummivarefabrik A/S, Aalborg, Denmark) and a thick layer of chopped straw. Cows had ad libitum 
access to water from self-filling water bowls, and fresh feed was provided every morning at $0700 \mathrm{~h}$ and topped up 3 times during the day at 1200, 1600, and 2000 h. Cameras (type TCVVD-600, Monacor, Bremen, Germany) were positioned over every individual pen, and a video analysis program (MSH-Video, M. Shafro and Co., Riga, Latvia) was used to record behaviors for individual cows and calves. For each cow, posture was continuously recorded. In addition, the time (min) from the first observation of each of the following until the delivery of the calf was recorded: first visible sign of rhythmical abdominal muscle contractions (defining start of stage II labor), first observation of the amniotic sac outside the cow's vulva, and first observation of the calf's feet outside the cow's vulva. Finally, time (s) from the delivery of the calf until the cow stood up after birth (Table 1) was recorded. Calving difficulty was scored by the farm staff as (1) easy, no assistance; (2) easy with assistance (a light pull with bare hands); (3) considerable assistance (use of obstetric chain or calf-jack); (4) considerable assistance by veterinarian, and (5) cesarean section.

The behavior of the calves was recorded from birth (the time of birth was defined as the calf being fully expelled or the calf's hips being expelled, leaving the hind legs inside the birth canal) until they successfully stood up or were removed from the maternity pen (10 to $18 \mathrm{~h}$ after birth). Calf vitality was assessed by 4 latency variables: (1) the time from birth to the calf's first standing attempt, (2) time from birth to the first successful standing, (3) time from birth to the first suckling attempt, and (4) time from birth to the first successful suckling event. All data were obtained from continuous video recordings. Two trained and experienced observers recorded all calf behavior variables, and 1 experienced observer recorded cow behavior variables. Before any data were collected, the 2 observers scored a sample of videos together to establish a baseline for all calf behavior observations.

\section{Data Editing and Statistical Analysis}

Cows. Cows were excluded if they calved in the FS (Holstein, $\mathrm{n}=4$; Jersey, $\mathrm{n}=2$ ) or in the DS (Holstein, $\mathrm{n}=13$; Jersey, $\mathrm{n}=5$ ), or if they spent less than $12 \mathrm{~h}$ in the maternity pen before calving (Holstein FS, $\mathrm{n}=$ 3; Holstein DS, $\mathrm{n}=7$; Jersey FS, $\mathrm{n}=1$; and Jersey DS, $\mathrm{n}=1$ ). Cows were also excluded if they had twins (Holstein FS, $\mathrm{n}=2$; Holstein DS, $\mathrm{n}=0$; Jersey FS, $\mathrm{n}=$ 1 ; and Jersey DS, $\mathrm{n}=0$ ), had a stillborn calf (Holstein $\mathrm{FS}, \mathrm{n}=0$; Holstein DS, $\mathrm{n}=3$; Jersey FS, $\mathrm{n}=1$; and Jersey DS, $\mathrm{n}=2$ ), or received considerable calving assistance (scored as $\geq 3$ on the calving difficulty scale; Holstein FS, $\mathrm{n}=2$; Holstein DS, $\mathrm{n}=2$; Jersey FS, $\mathrm{n}=$ 1 ; and Jersey DS, $\mathrm{n}=0$ ). No cows received veterinary assistance or were in need of a cesarean during calving throughout the study. Three cows had to be excluded due to disturbances in the barn around calving (Holstein FS, $\mathrm{n}=1$; Holstein DS, $\mathrm{n}=2$; Jersey FS, $\mathrm{n}=0$; and Jersey DS, $\mathrm{n}=0$ ). Finally, 14 cows (Holstein FS, $\mathrm{n}=7$; Holstein DS, $\mathrm{n}=2$; Jersey FS, $\mathrm{n}=1$; and Jersey $\mathrm{DS}, \mathrm{n}=4$ ) were excluded due to video equipment failure. Thus, the final analysis included 39 multiparous cows (Holstein FS, $\mathrm{n}=13$; Holstein DS, $\mathrm{n}=11$; Jersey $\mathrm{FS}, \mathrm{n}=9$; Jersey DS, $\mathrm{n}=6$ ) and 15 primiparous cows (Holstein FS, $\mathrm{n}=5$; Holstein DS, $\mathrm{n}=5$; Jersey FS, $\mathrm{n}=3$; Jersey DS, $\mathrm{n}=2$ ). Ten cows calved standing up due to human interference during calving assistance and were therefore removed from the analysis of latency to stand and latency to lick the calf after delivery. For 6 cows, the amniotic sac was not seen and could not be registered, and for 3 cows, calf feet were not seen due

Table 1. Ethogram of cow postures, behaviors, calving events, and calf behavior and postures

\begin{tabular}{|c|c|c|}
\hline Variable & Level & Definition \\
\hline Standing & Posture & Standing or walking with body supported by at least 3 legs \\
\hline Lying & Posture & Lying fully on its side or on sternum \\
\hline First visible amniotic sac & Calving event & The amniotic sac is visible for the first time \\
\hline First visible calf feet & Calving event & Calf feet are visible for the first time \\
\hline Lying & Posture & Calf is lying fully on its side or upright on sternum \\
\hline Standing attempt & Behavioral event & $\begin{array}{l}\text { Calf is partially standing upright with both hind legs extended and with front legs still } \\
\text { under body but without reaching fully upright position }\end{array}$ \\
\hline First successful standing & Behavioral event & Calf is standing upright with all 4 legs fully extended for longer than $5 \mathrm{~s}$ \\
\hline Suckle attempt & Behavior & $\begin{array}{l}\text { While standing, calf is positioned below standing cow with head located under the } \\
\text { front of the cow's body }\end{array}$ \\
\hline
\end{tabular}


to the position of the cow relative to the camera. Ten cows had their calves moved in front of them by staff immediately after birth, and these cows were therefore omitted from the analysis of cows' latency to lick the calf.

Calves. Calves from dams that spent less than $12 \mathrm{~h}$ in the maternity pen were included in the data (Holstein FS, $\mathrm{n}=3$; Holstein DS, $\mathrm{n}=7$; Jersey FS, $\mathrm{n}=1$; and Jersey DS, $n=1$ ). However, 2 calves were excluded due to broken legs and 1 calf died due to crushing by the dam soon after birth. Finally, 4 calves were excluded due to video equipment failure. Forty-nine calves from multiparous cows (Holstein FS, $\mathrm{n}=18$; Holstein DS, $\mathrm{n}=13$; Jersey FS, $\mathrm{n}=10$; Jersey DS, $\mathrm{n}=8)$ and 25 calves from primiparous cows (Holstein FS, $\mathrm{n}=10$; Holstein DS, $\mathrm{n}=7$; Jersey FS, $\mathrm{n}=3$; Jersey DS, $\mathrm{n}=$ 5 ) were included in the final analysis.

All statistical analyses were performed using SAS software (version 9.3; SAS Institute Inc., Cary, NC). None of the variables could be assumed normally distributed and were transformed using the natural logarithm before statistical analysis. Assumptions of normality were controlled by residual plots. An ANOVA (PROC MIXED) was used to determine the effect of housing before calving on the calving progress using time from first visible abdominal contraction, first observation of the amniotic sac, and first observation of calf feet to birth, as well as the cow's latency to stand after birth. The model included treatment (FS, DS), breed (Holstein, Jersey), parity (primiparous, multiparous), and calving assistance [no assistance (score 1), assistance (score 2)], and all 2-way interactions for each of the investigated variables. For calf data, the model also in-

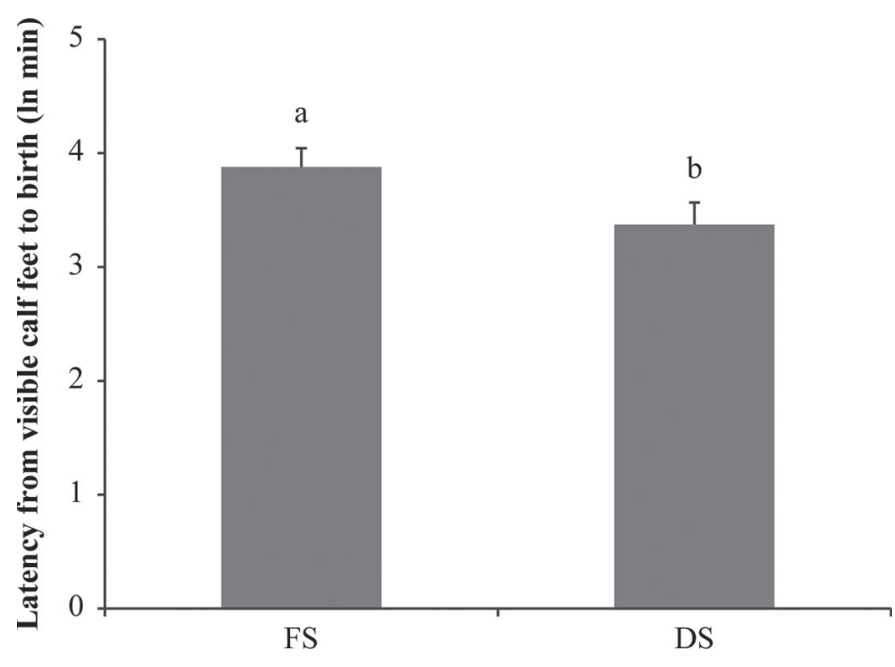

Figure 1. Latency from visible calf feet to birth (ln $\mathrm{min}$ ) for freestall ( $\mathrm{FS} ; \mathrm{n}=31$ ) and deep-bedded straw pack ( $\mathrm{DS} ; \mathrm{n}=24$ ) cows. Different letters indicate a significant difference between treatments $(P$ $<0.05)$. Error bars show standard error of the mean. cluded observer as an explanatory variable. This model was used to determine the effect of the previous housing of the dam on calf vitality using the latency from birth to the calf's first standing attempt, to first successful standing, to first suckle attempt, and to first successful suckling. A PDIFF statement was used to identify significant interactions. All given estimates are given as ln-transformed least squares means (LSM) \pm standard errors (SE), whereas back-transformed LSM values are given in text. To investigate whether the number of assisted calvings differed between breed, treatment, or parity, a one-way Chi-square goodness-of-fit test was used. For nonsignificant variables, medians and quartiles are given; $P$-values are considered significant at $<0.05$ and tendencies at $<0.09$. Back-transformed values of all dependent variables of Figures 1 to 3 are presented in Table A1 of the Appendix.

\section{RESULTS}

\section{Cows}

Cows that had been housed in DS for the last 4 wk before calving had a shorter expulsion time (29 min) from when calf feet were first visible until birth compared with FS cows (48 $\mathrm{min} ; F_{1,44}=4.23, P=$ 0.05; Figure 1). Jersey cows licked their calves sooner after calving compared with Holstein cows $(-0.62 \pm$ 0.4 vs. $\left.0.01 \pm 0.3 \mathrm{~min} ; F_{1,31}=4.58, P=0.04\right)$; backtransformed mean values were $30 \mathrm{~s}$ for Jersey cows and $60 \mathrm{~s}$ for Holstein cows. Multiparous cows licked their calves sooner after calving compared with primiparous cows $\left(-0.8 \pm 0.3\right.$ vs. $0.2 \pm 0.4 \mathrm{~min} ; F_{1,31}=7.17, P=$ 0.01 ); back-transformed mean values were $27 \mathrm{~s}$ for multiparous cows and $73 \mathrm{~s}$ for primiparous cows. Cows that received calving assistance tended to lick their calves sooner than unassisted cows $(-0.9 \pm 0.6$ vs. $0.3 \pm 0.2$ $\min ; F_{1.31}=3.47, P=0.07$ ); back-transformed mean values were $25 \mathrm{~s}$ for cows with calving assistance and 81 $\mathrm{s}$ for cows without calving assistance.

Holstein DS cows tended to stand sooner after expulsion of the calf compared with FS Holstein $(-0.3 \pm 0.4$ vs. $0.6 \pm 0.4 \mathrm{~min}$; treatment $\times$ breed, $F_{1,38}=3.27, P$ $=0.08)$; back-transformed mean values were $44 \mathrm{~s}$ for DS cows and $109 \mathrm{~s}$ for FS cows. Multiparous Holstein cows tended to stand sooner than primiparous Holstein cows $(-0.1 \pm 0.3$ vs. $0.4 \pm 0.5$ min; breed $\times$ parity, $\left.F_{1,38}=3.32, P=0.08\right)$; back-transformed mean values were $54 \mathrm{~s}$ for multiparous Holstein cows and $89 \mathrm{~s}$ for primiparous Holstein cows. Multiparous Jersey cows tended to stand sooner after calving than primiparous Jersey cows $(-0.8 \pm 0.4$ vs. $1.3 \pm 0.7 \mathrm{~min}$; breed $\times$ parity, $\left.F_{1,38}=3.32, P=0.08\right)$; back-transformed mean values were $27 \mathrm{~s}$ for multiparous Jersey cows and 220 
$\mathrm{s}$ for primiparous Jersey cows. Fourteen Holstein cows required calving assistance compared with 4 Jersey cows ( $\mathrm{df}=1, \chi^{2}=5.56, P=0.03$ ), and no difference between treatments or parity was found.

No effect of treatment or breed was found for the time from start of rhythmical contractions until calving; that is, the length of stage II labor [median (range): 114 (79 to 151 ) $\min ; P>0.10$ ] or time from visible amniotic sac to the expulsion of the calf [60 (38 to 100) min; $P>0.10]$. Freestall animals were generally moved to the maternity pen earlier before calving [4 (3 to 5$)$ d] compared with DS animals [2 (1 to 3 ) d; $P<0.05$ ], but we detected no significant difference in moving time between breeds.

\section{Calves}

A treatment $\times$ breed interaction was found for calf latency to stand after birth $\left(F_{1,61}=7.38, P=0.01\right.$; Figure 2), in which DS Jersey, FS Holstein, and DS Holstein calves stood up sooner after birth compared with FS Jersey calves. A treatment $\times$ breed interaction was found for the latency to suckle the dam after birth, where FS Holstein calves suckled sooner after birth compared with FS Jersey calves $\left(F_{1,56}=4.05, P=\right.$ 0.05; Figure 3). Calves born without calving assistance tended to make standing attempts sooner than calves born with calving assistance $(2.7 \pm 0.2$ vs. $3.1 \pm 0.1$ $\min ; F_{1.62}=3.06, P=0.09$ ); back-transformed mean values were $14.9 \mathrm{~min}$ for calves without calving assistance and 22.2 min for calves with calving assistance. No difference in the latency to the first suckle attempt was found regardless of breed or treatment [median (25th -75 th quartile): 16 (11 to 32 ) min; $P>0.10$ ].

\section{DISCUSSION}

Cows that had been housed in pens with deep straw bedding (DS) during the last 4 wk before calving had a shorter time span from when a calf's feet were first visible until the calf was born compared with animals housed in freestalls (FS). Among Holstein cows, those cows that were on DS tended to stand sooner than cows in FS. This suggests that housing dry cows in straw pens rather than in freestalls for the last 4 wk before calving may have a positive effect on the progress of this final stage of labor.

\section{Cows}

Cows on DS had a shorter latency from visible calf feet until calving compared with FS cows. The estimated mean latency from visible calf feet to calving was, on average, 19 min shorter for cows housed on

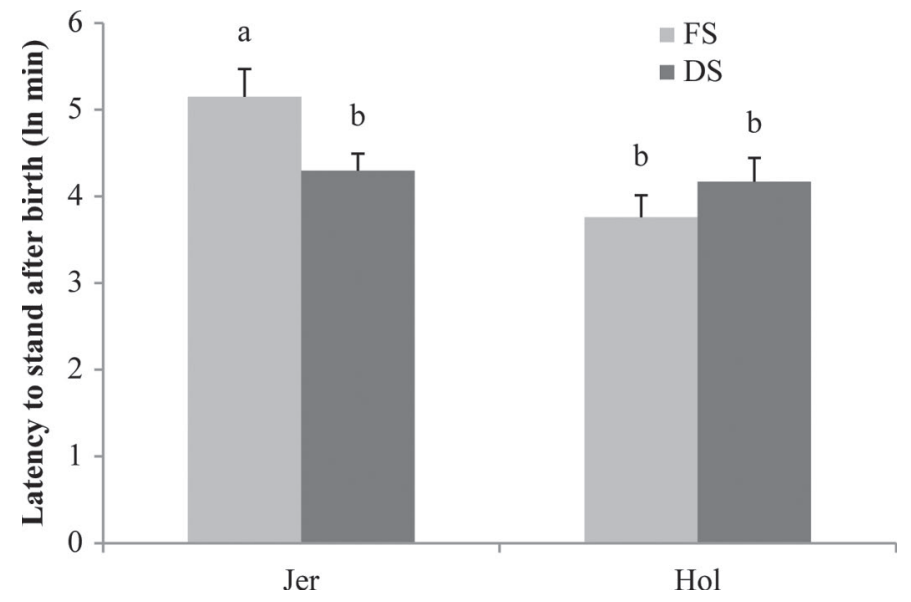

Figure 2. Latency for the calf to stand up after birth (ln min) for Jersey [freestall (FS), $\mathrm{n}=12$; deep-bedded straw pack (DS), $\mathrm{n}=8$ ] and Holstein (FS, $\mathrm{n}=19$; DS, $\mathrm{n}=16$ ) cows. Different letters indicate a significant difference between treatments $(P<0.05)$. Error bars show standard error of the mean.

DS compared with cows housed in FS before calving. All cows calved in individual straw-bedded maternity pens, thus any differences were due to previous housing (FS or DS). During the final 4 wk before calving, DS cows changed posture from standing to lying more often compared with FS cows (Campler, 2014), which illustrates that the DS housing placed less restriction on postural changes than the FS housing. However, the more frequent postural changes, and possibly increased locomotion on the DS, may also have improved muscular strength of the cows, which could explain the shorter duration of the final stage of labor in DS cows. This is supported by studies in humans (Prather et al.,

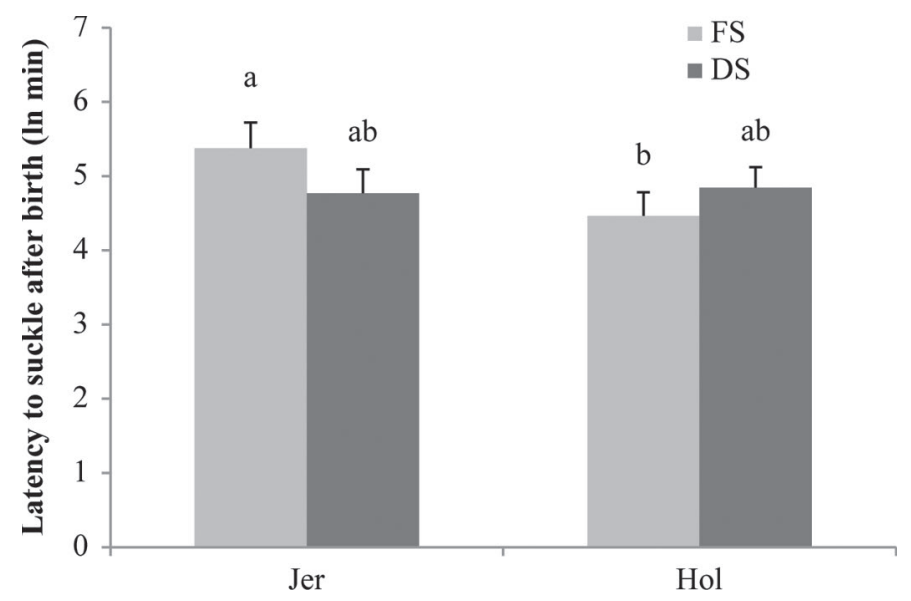

Figure 3. Latency for the calf to suckle the dam after birth (ln min) for Jersey [freestall (FS), $\mathrm{n}=12$; deep-bedded straw pack (DS), $\mathrm{n}=8]$ and Holstein (FS, $\mathrm{n}=19$; DS, $\mathrm{n}=16$ ) cows. Different letters indicate a significant difference between treatments $(P<0.05)$. Error bars show standard error of the mean. 
2012; Szumilewicz et al., 2013; Domenjoz et al., 2014). The latencies from visible calf feet until calving in our study are similar to those in Schuenemann et al. (2011), who reported a mean time of 40 min from visible calf feet to expulsion of the calf for cows that calved unassisted, and are within the same range as reported by Barrier et al. (2012), who reported a mean time of 55 min from visible calf feet to birth. Despite the shorter duration from visible calf feet to calving in DS cows, we found no difference for the onset of the second stage of labor or in the latency from when the amniotic sac was visible until birth. This may be explained by these events being difficult to determine from video recordings, whereas calf feet are easily detected. Our estimate of the duration of the second stage of labor was approximately $110 \mathrm{~min}$. This is higher than the findings of Schuenemann et al. (2011), who reported durations of stage II around $60 \mathrm{~min}$ for Holstein cows housed on straw, whereas Proudfoot et al. (2013) reported durations of 60 and 90 min for Holstein cows moved well in time before labor and late in the first stage of labor, respectively. It has been reported that the first stage of labor may be initiated as early as $24 \mathrm{~h}$ before expulsion of the calf (Jackson, 2004).

Another factor that may have affected ease of calving was that DS cows were moved to the maternity pen closer to calving than FS cows, which allowed FS cows to spend more time in the maternity pen before calving. Heuwiser et al. (1987) found that cows moved into a maternity pen $3 \mathrm{~d}$ before calving had lower levels of glucocorticoid concentrations at calving compared with cows moved close to calving, suggesting a lower stress level in cows that had time to adapt to the maternity pen. On the other hand, the DS cows were kept in pens next to the maternity pens and had a good view of these during the last $4 \mathrm{wk}$ before calving, making differences in habituation less likely. The onset of labor is recognized by relaxation of the pelvic ligaments and an enlarged udder (Noakes et al., 2001), and these physical changes are associated with increased restlessness (Jensen, 2012) and a raised tail (Miedema et al., 2011). Proudfoot et al. (2013) found that cows that were moved to an individual maternity pen with these early signs, or before any signs, of calving experienced shorter labor than cows moved closer to the time of calving. Thus, the timing of movement to a maternity pen is a management practice that affects ease of calving; similar effects have been reported in sows (Pedersen and Jensen, 2008). However, we excluded cows that were moved less than $12 \mathrm{~h}$ before calving to avoid the possibility that the moving procedure itself could have affected the progress of labor. Although DS and FS cows were moved based on the same criteria, FS cows spent 2 more days in the maternity pen before calving compared with DS cows, which may be due to FS cows being moved a longer distance and this delaying calving. However, this requires further investigation.

After the birth of the calf, multiparous cows of both breeds stood up and licked their calves sooner compared with primiparous cows. Previous studies have reported that primiparous cows generally have more difficult calvings and a longer duration of the second stage of labor compared with multiparous cows (e.g., Meyer et al., 2001; Noakes et al., 2001), although no effect of parity on ease of calving was seen in the present study. However, the latency from calving until the cow licked the calf was longer in primiparous cows. In a previous study with only multiparous cows, second-parity cows had a longer latency to stand and to lick their calf than later-parity cows (Jensen, 2012), and another study has shown that experienced dams lick their calves for longer compared with inexperienced dams (Le Niendre, 1989), suggesting that maternal experience is an important factor for cows' motivation to attend to their offspring. We found that Jersey cows in the current study licked their calves sooner compared with Holstein cows, and this finding may be a breed difference in maternal motivation, but this requires further studies.

We detected no breed effects on the duration of labor, but more Holstein cows than Jersey cows required calving assistance. This difference may be an effect of a higher incidence of feto-pelvic disproportion in the larger Holstein breed (Mee, 2008), a measurement not recorded in our study.

\section{Calves}

An interaction between housing and breed was observed on calf vitality. The hypothesis was that calves that were born from dams with an easier labor process would be more active and would therefore stand and suckle sooner than calves from dams with a longer labor. Despite DS cows' shorter latency from visible calf feet to birth, we observed no overall effect of dam's housing treatment before calving on the calving process. However, FS Jersey calves took longer to stand compared with other calves and took longer to suckle compared with FS Holstein calves. These breed differences require further investigation. A previous study observed calves' first standing attempt at $21 \mathrm{~min}$ and successful standing around $51 \mathrm{~min}$ after being born (Jensen, 2012). However, the average time it took for calves to stand in the present study was higher (124 min) and more in line with findings of Houwing et al. (1990), who reported calves successfully standing within 88 to $152 \mathrm{~min}$. The latency for calves to stand 
is thought to be linked to the licking behavior of the dam shortly after birth (Lidfors, 1996). The licking of the calf serves to dry the calf's coat but also helps to form a bond between the dam and the calf (Illmann and Ŝpinka, 1993; von Keyserlingk and Weary, 2007).

Calves that received no calving assistance tended to stand sooner than calves that received calving assistance, which is in accordance with a previous report (Odde, 1988). During a difficult calving, the calf is at risk of hypoxia, which could reduce its chance of survival or even be fatal (House, 2002). There is also the risk that the additional force applied during assisted delivery may cause the calf injury and pain and thus reduce calf vitality (Schuijt, 1990; Murray and Leslie, 2013). In our study, although calves from dams that needed considerable calving assistance $(\geq 3$ on the calving assistance scale) were excluded, we found a tendency for even a lightly assisted calving (score 2 on the calving assistance scale) to negatively affect the calf's condition and vitality.

Latency to suckle is linked to latency to stand because a calf that is standing earlier is more likely to suckle earlier. Therefore, the longer latency to suckle seen in FS Jersey calves compared with FS Holstein calves is most likely explained by the latency to stand in FS Jersey calves. For comparison, Ventorp and Michanek (1991) reported that all calves, among 21 Holstein dams and calves housed in individual maternity pens with straw, successfully suckled within approximately 4 $\mathrm{h}$ after birth, which is twice the time recorded for our Holstein calves but in the range for latencies shown by our Jersey calves.

\section{CONCLUSIONS}

In this study, a 4-wk period of housing in a pen with deep straw bedding before calving compared with freestalls decreased the time it took from when the calf's legs were visible until expulsion of the calf in both Holstein and Jersey cows. We conclude, from this study, that housing of the dam before calving may have an effect on the calving process. However, the potential effect on the vitality of the newborn calf under these circumstances was only observed in Jersey calves, not in Holstein calves, and needs to be investigated further.

\section{ACKNOWLEDGMENTS}

The authors greatly acknowledge the help from the farm staff and technicians throughout this experiment. The work was supported by the Danish Cattle Federation (Aarhus, Denmark), the Danish Ministry of Food, Agriculture and Fisheries (Copenhagen, Denmark).

\section{REFERENCES}

Barrier, A. C., M. J. Haskell, A. I. Macrae, and C. M. Dwyer. 2012. Parturition progress and behaviours in dairy cows with calving difficulty. Appl. Anim. Behav. Sci. 139:209-217.

Calamari, L., F. Calegari, and L. Stefanini. 2009. Effect of different free stall surfaces on behavioural, productive and metabolic parameters in dairy cows. Appl. Anim. Behav. Sci. 120:9-17.

Campler, M. 2014. The effect of housing on dairy cattle behavior during the transition period. PhD Thesis. Aarhus Univ., Denmark.

Campler, M., L. Munksgaard, M. B. Jensen, D. M. Weary, and M. A. G. von Keyserlingk. 2014. Flooring preferences of dairy cows at calving. J. Dairy Sci. 97:892-896.

Clapp, J. F., III. 1990. The course of labor after endurance exercise during pregnancy. Am. J. Obstet. Gynecol. 163:1799-1805.

Cook, N. B., T. B. Bennett, and K. V. Nordlund. 2004. Effect of free stall surface on daily activity patterns in dairy cows with relevance to lameness prevalence. J. Dairy Sci. 87:2912-2922.

Domenjoz, I., B. Keyser, and M. Boulvain. 2014. Effect of physical activity during pregnancy on mode of delivery. Am. J. Obstet. Gynecol. 401:e1-11.

Ferket, S. L., and R. R. Hacker. 1985. Effect of forced exercise during gestation on reproductive performance of sows. Can. J. Anim. Sci. 65:851-859.

Fregonesi, J. A., M. A. G. von Keyserlingk, and D. M. Weary. 2009. Cow preference and usage of free stalls compared with an open pack area. J. Dairy Sci. 92:5497-5502.

Grummer, R. R. 1995. Impact of changes in organic nutrient metabolism on feeding the transition dairy cow. J. Anim. Sci. 73:28202833.

Hale, O. M., C. V. Booram, and W. C. McCormick. 1981. Effects of forced exercise during gestation on farrowing and weaning performance of swine. J. Anim. Sci. 52:1240-1243.

Heuwiser, W., U. Hartig, and F. Offeney. 1987. Importance of glucocorticoids as measures of stress in cattle in the periparturient period. J. Vet. Med. A 34:178-187.

House, J. K. 2002. Perinatal adaptation, asphyxia, and resuscitation. Pages 266-267 in Large Animal Internal Medicine. 3rd ed. B. P. Smith, ed. Mosby, St. Louis, MO.

Houwing, H., J. F. Hurnik, and N. J. Lewis. 1990. Behavior of periparturient dairy cows and their calves. Can. J. Anim. Sci. 70:355-362.

Illmann, G., and M. Ŝpinka. 1993. Maternal behaviour of dairy heifers and sucking of their newborn calves in group housing. Appl. Anim. Behav. Sci. 36:91-98.

Jackson, P. G. G. 2004. Normal birth. Pages 1-12 in Handbook of Veterinary Obstetrics. 2nd ed. Saunders, Philadelphia, PA.

Jensen, M. B. 2012. Behaviour around the time of calving in dairy cows. Appl. Anim. Behav. Sci. 139:195-202.

Lamb, R. C., B. O. Barker, M. J. Anderson, and J. L. Walters. 1979. Effects of forced exercise on two-year-old Holstein heifers. J. Dairy Sci. 62:1791-1797.

Le Niendre, P. 1989. Influence of cattle rearing conditions and breed on social relationships of mother and young. Appl. Anim. Behav. Sci. 23:117-127.

Lidfors, L. M. 1996. Behavioural effects of separating the dairy calf immediately or 4 days post-partum. Appl. Anim. Behav. Sci. 49:269-283.

Lidfors, L. M., D. Moran, J. Jung, P. Jensen, and H. Castren. 1994. Behaviour at calving and choice of calving place in cattle kept in different environments. Appl. Anim. Behav. Sci. 42:11-28.

Livesey, C. T., C. Marsh, J. A. Metcalf, and R. A. Laven. 2002. Hock injuries in cattle kept in straw yards or cubicles with rubber mats or mattresses. Vet. Rec. 150:677-679.

Mee, J. F. 2008. Prevalence and risk factors for dystocia in dairy cattle: A review. Vet. J. 176:93-101.

Meyer, C. L., P. J. Berger, K. J. Koehler, J. R. Thompson, and C. G. Sattler. 2001. Phenotypic trends in incidence of stillbirth for Holsteins in the United States. J. Dairy Sci. 84:515-523.

Miedema, H., S. M. Cockram, C. M. Dwyer, and A. I. Macrae. 2011. Changes in the behaviour of dairy cows during the $24 \mathrm{~h}$ before 
normal calving compared with behaviour during late pregnancy. Appl. Anim. Behav. Sci. 131:8-14.

Mulligan, F. J., and M. L. Doherty. 2008. Production diseases of the transition cow. Vet. J. 176:3-9.

Murray, C. F., and K. Leslie. 2013. Newborn calf vitality: Risk factors, characteristics, assessment, resulting outcomes and strategies for improvement. Vet. J. 198:322-328.

Noakes, D. E., T. J. Parkinson, G. C. W. England, and G. H. Arthur. 2001. Parturition and the care of parturient animals. Page 155-187 in Arthur's Veterinary Reproduction and Obstetrics. 8th ed. Saunders, Philadelphia, PA

Odde, K. G. 1988. Survival of the neonatal calf. Vet. Clin. North Am. Food Anim. Pract. 4:501-508.

Pedersen, L. J., and T. Jensen. 2008. Effects of late introduction to two farrowing environments on the progress of farrowing and maternal behaviour. J. Anim. Sci. 86:2730-2737.

Phillips, C. J. C., and S. A. Schofield. 1994. The effect of cubicle and straw yard housing on the behaviour, production and hoof health dairy cows. Anim. Welf. 3:37-44.

Prather, H., T. Spitznagle, and D. Hunt. 2012. Benefits of exercise during pregnancy. PM R 4:845-850.

Proudfoot, K. L., M. B. Jensen, P. M. H. Heegaard, and M. A. G. von Keyserlingk. 2013. Effect of moving dairy cows at different stages of labor on behavior during parturition. J. Dairy Sci. 96:16381646.

Schuenemann, G. M., I. Nieto, S. Bas, K. N. Galvão, and J. Workman. 2011. Assessment of calving progress and reference times for obstetric intervention during dystocia in Holstein dairy cows. J. Dairy Sci. 94:5494-5501.

Schuijt, G. 1990. Iatrogenic fractures of ribs and vertebrae during delivery in perinatally dying calves: 235 cases (1978-1988). J. Am. Vet. Med. Assoc. 197:1196-1202.

Szumilewicz, A., A. Wojtyla, A. Zarębska, I. Drobnik-Kozakiewicz, M. Sawczyn, and A. Kwitniewska. 2013. Influence of prenatal physical activity on the course of labour and delivery according to the new Polish standard for perinatal care. Ann. Agric. Environ. Med. 20:380-389.

Tucker, C. B., D. M. Weary, and D. Fraser. 2003. Effects of three types of free-stall surfaces on preferences and stall usage by dairy cows. J. Dairy Sci. 86:521-529.

Ventorp, M., and P. Michanek. 1991. Cow-calf behaviour in relation to first suckling. Res. Vet. Sci. 51:6-10

von Keyserlingk, M. A. G., and D. M. Weary. 2007. Maternal behavior in cattle. Horm. Behav. 52:106-113.

Weary, D. M., and I. Taszkun. 2000. Hock lesions and free-stall design. J. Dairy Sci. 83:697-702.

\section{APPENDIX}

Table A1. Back-transformed values (min) for all dependent variables in Figures 1 to $3^{1}$

\begin{tabular}{|c|c|c|c|c|}
\hline \multirow[b]{2}{*}{ Figure 1} & \multicolumn{2}{|c|}{ FS } & \multicolumn{2}{|c|}{ DS } \\
\hline & \multicolumn{2}{|c|}{$48^{\mathrm{a}}$} & \multicolumn{2}{|c|}{$29^{\mathrm{b}}$} \\
\hline & \multicolumn{2}{|c|}{ Jersey } & \multicolumn{2}{|c|}{ Holstein } \\
\hline & FS & DS & FS & DS \\
\hline Figure 2 & $172^{\mathrm{a}}$ & $74^{\mathrm{b}}$ & $43^{\mathrm{b}}$ & $65^{\mathrm{b}}$ \\
\hline Figure 3 & $215^{\mathrm{a}}$ & $118^{\mathrm{ab}}$ & $87^{\mathrm{b}}$ & $127^{\mathrm{ab}}$ \\
\hline
\end{tabular}

${ }^{\mathrm{a}, \mathrm{b}}$ Different letters within row indicate differences between or among means of the natural log-transformed data $(P<0.05)$.

${ }^{1} \mathrm{FS}=$ freestalls; $\mathrm{DS}=$ deep-bedded straw pack. 